\title{
Developing an integrated conceptual framework for monitoring and controlling risks related to occupational health and safety
}

\author{
Nazli Gulum Mutlu* and Serkan Altuntas** \\ * Department of Occupational Health and Safety, Bingol University, Bingol, 12000, Turkey \\ ** Yildiz Technical University, Department of Industrial Engineering, , Istanbul, 34349, Turkey \\ *Corresponding Author :ngmutlu@bingol.edu.tr
}

Submitted : 17/03/2020

Revised :01/05/2021

Accepted :09/05/2021

\begin{abstract}
There is a strong relationship between monitoring and controlling risks from several perspectives and developing effective measures to ensure continuous improvement by creating value in occupational health and safety. Business systems that transform into complex and sociotechnical systems have a dynamic structure and contain various serious risks that threaten employee health and safety based on the technological development. Even if the risk impact is reduced with the classical attempts of occupational safety experts to prevent losses, new risks may arise owing to missed risks. Therefore, risks must be continuously monitored and controlled with functionally complementary tools. In addition, these tools must interact with each other. Achieving effective results from their effort in coping with risks is another key factor for businesses. In this paper, an integrated conceptual framework for monitoring and controlling risks in occupational health and safety is proposed. The proposed framework consists of four parts. The hypothesis proposed in the first part focuses on learning from accidents, and that proposed in the second part is related to the proactive analysis and evaluation of risks. The hypothesis proposed in the third part deals with the correct ranking of risks, and that proposed in the fourth part focuses on the development of an early-warning system based on safety technologies. The hypotheses should interact and support each other in the integrated conceptual framework. Finally, the safety performance can be enhanced, and continuous improvement can be achieved by preventing the waste of time and resources.
\end{abstract}

Keywords: Conceptual framework; Continuous improvement; Monitoring and controlling risks; Occupational health and safety; Safety performance.

\section{INTRODUCTION}

There is a strong relationship between monitoring and controlling risks from several perspectives and developing effective measures to ensure continuous improvement by creating value in occupational health and safety. Business systems that transform into complex systems have a dynamic structure and contain various serious risks that threaten employee health and safety based on the technological development. Even if the risk impact is reduced with the classical attempts of occupational safety experts to prevent losses, new risks may arise owing to missed risks. Therefore, risks must be continuously monitored and controlled with functionally complementary tools. In addition, 
these tools must interact with each other. Achieving effective results from their effort in coping with risks is another key factor for businesses. In this paper, an integrated conceptual framework for monitoring and controlling risks in occupational health and safety is proposed. The proposed framework consists of four parts. The hypothesis proposed in the first part focuses on learning from accidents, and that proposed in the second part is related to the proactive analysis and evaluation of risks. The hypothesis proposed in the third part deals with the correct ranking of risks, and that proposed in the fourth part focuses on the development of an early-warning system based on safety technologies. The hypotheses should interact and support each other in the integrated conceptual framework. The safety performance can be enhanced and continuous improvement can be achieved by preventing the waste of time and resources.

Production systems have turned into complex systems with serious risks threatening employee health and safety. In the face of this transformation, theoretical and practical regulations on occupational health and safety have not shown flexibility (Badri et al., 2018). Consequently, serious costs have been paid by experiencing work accidents, occupational diseases, and even major industrial accidents. Recognized as a milestone for the historical development of occupational health and safety, the first law is the law of factories, which is also known as the apprenticeship law published in 1802 in the United Kingdom (Singpurwalla and Wilson, 2008). Legal regulations on occupational health and safety have been established in the United States since the 1900s (Goetsch, 2015, p. 25). In 1919, the International Labor Organization (ILO) was established in 187 countries, thereby bringing together employers under a single roof, setting standards, and regulating working life. The ILO develops policies and sets standards for working life. The importance of occupational health and safety has been emphasized worldwide after the establishment of the International Organization for Standardization (ISO), which started its operations in 1947 and has published more than 22,810 standards, and the Occupational Safety and Health Administration (OSHA) in 1970 to develop healthy and safe working conditions for employees. In addition to the developments in legal regulations, accepted work accident theorems have been published. Khanzode et al. (2012) classified the accident theories as follows: (1) first generation: accident proneness theory, (2) second generation: domino theory, (3) third generation: injury epidemiology theory, (4) fourth generation: system theories, sociotechnical system theory, and macro ergonomic theory. Similar to the change in accident theories, work accident analysis approaches have changed over time. In addition, statistical inferences have been made with accident analyses (e.g., Erdugan \& Türkan, 2017, Turkkan \& Pala, 2016, Ceylan, 2012 \& Swaen et al., 2003) and many data mining-based approaches have been published (Sarkar et al., 2019; Altunkaynak, 2018, Shin et al., 2018 \& Sarkar et al., 2016b). As can be seen from previous studies, authors used accident records for the analysis of risks related to occupational health and safety. In addition, the analysis of risks related to occupational health and safety based on accident records can help to prevent the recurrence of similar accidents and to strengthen preventative measures (Jung et al., 2020). In this study, a conceptual framework consisting of four hypotheses is proposed to reduce losses due to accidents and injuries in industries that suffer from monitoring and controlling risks. The first hypothesis of the conceptual framework proposed in this paper suggests that researchers should analyze the accident records with data mining-based approaches to determine the most important risk factors for accidents, to take into account the accident rules consisting of important accident factors, and to develop security measures.

Despite the pleasing developments in occupational health and safety, occupational accidents continue to occur. Another integral part of occupational health and safety management is risk analyses and evaluation practices (Vranješ \& Todić, 2019). Marhavilas and Koulouriotis (2012, p.51) defined risk assessment as an essential and systematic process for assessing the impact, occurrence, and consequences of human activities for systems with hazardous characteristics. In addition, Moraru (2012) pointed out that risk analyses can identify weaknesses, consider and correct these weaknesses, and continuously improve the safety performance of systems. Risk analyses and management have been conducted for 30-40 years and remain a developing field (Aven, 2016). Therefore, many risk analysis and assessment methods have been developed to ensure safety in industrial plants (Tixier et al., 2002 \& Gul, 2018). However, according to literature, the methods do still not meet the requirements in practice, and further 
research is necessary (Kjellén \& Sklet, 1995, Hauke et al., 2011, \& Marhavilas et al., 2011). Furthermore, Khanzode \& Maiti (2012) pointed out that the risk analysis methods and accident analyses are independent of each other and should be intersected. Kjellen \& Sklet (1995) criticized the inconsistency between the criteria used in risk analyses and assessment methods and the causes of accidents. Consequently, the second hypothesis of the conceptual framework proposed in this paper suggests that researchers should consider these accidents and include them in a proactive risk analysis and evaluation process.

Another criterion to be met through a risk analysis and evaluation is the degree of risk. The degree of risk is expressed as a combination of the probability and severity of risks (Ristić, 2013). It also indicates the relative importance of risks to each other. The degree or sequence of risks helps managers to determine preventive measures (Ouédraogo et al., 2011), and reliable risk ranking improves the safety performance (Alyami et al., 2019). Literature provides many risk prioritization or rating methods (e.g., Dabbagh \& Yousefi, 2019, Oz et al., 2019, Podgórski, 2015; Gul et al., 2017, Balaraju et al., 2019 \& Zhang et al., 2019a). The common objective of risk prioritization/rating methods is to ensure that the corrective actions eliminate or reduce the risks by starting with the highest-priority risk (Dabbagh \& Yousefi, 2019 \& Balaraju et al., 2019). However, different risk assessment methods for the same failure types can lead to inconsistent risk sequencing (e.g., Song et al., 2013, Kutlu \& Ekmekçioğlu, 2012, Sachdeva et al., 2009 \& Braglia, 2000). This inconsistency is a major challenge for decision-makers. Therefore, the third hypothesis of the conceptual framework proposes the use of data fusion approaches such as the technique of precise order preference (TPOP), which can easily integrate the risk rankings obtained by multiple risk analysis and evaluation methods in practice.

The fourth hypothesis proposed within the conceptual framework concerns safety technologies in the field of occupational health and safety. According to literature, the effects of technological developments in the occupational health and safety field can be expressed in two dimensions. These dimensions are the diversification of risk types, which have increased concurrently with the industrial development (Tixier et al., 2002); occupational health and safety practices and employees are inflexible in these situations, and employees are exposed to accidents (Song \& Suh, 2019, Badri et al., 2018 \& Fernández et al., 2015). The use of technological tools for improving occupational health and safety has become extremely important in today's increasingly complex businesses (Dündar, 2018). Many studies of the effectiveness of safety technologies regarding employees have been conducted (e.g., Antwi-Afari, 2019, Gao et al., 2019, Holte et al., 2018, Awolusi et al., 2018, Badri et al., 2018 \& Yavuz, 2018), and the development of safety technologies has been investigated (e.g., Dehghani Madvar et al., 2019, Tatić \& Tešić, 2017, Niu et al., 2019, Wu \& Liz, 2019, Zhou et al., 2018 \& Podgorski et al., 2017). The monitoring and forecasting technologies developed to ensure occupational health and safety in production and service systems will be an inspiration for the required technologies in this field. This can open the opportunity to make its legal arrangements compatible with the technological developments and changes. For this purpose, the focus is monitoring safety technologies, obtaining information that support the required investment decisions, and providing opportunities for updating legal regulations. Therefore, an approach based on a patent data analysis is suggested in the last hypothesis of the conceptual framework.

The proposed integrated conceptual framework for monitoring and controlling risks can be considered a mechanism that provides information and data flow and feeds itself for the continuous development of organization.

Improving the safety performance is crucial for the sustainability of enterprises (Bastan et al., 2018 \& Zhang et al., 2019b). The proposed conceptual framework is expected to enable the reliable monitoring and control of risks and a proactive identification of the required measures; in addition, it should ensure continuous improvement. 


\section{LITERATURE REVIEW AND DEVELOPMENT OF HYPOTHESES}

Several researchers have proposed conceptual frameworks in the field of occupational health and safety. For instance, Kruse et al. (2019) proposed a single integrated lean management system based on the Environmental Management System (ISO 14001), Occupational Health and Safety Assessment Series (OHSAS 18001), EcoManagement and Audit Scheme, American National Standards Institute (ANSI Z10), California Injury and Illness Prevention Program (CA-IIPP), and Occupational Safety and Health Administration's Voluntary Protection Program (OSHA VPP). Moreover, Fitriani and Latief (2019) introduced a conceptual framework based on a construction project management theory, regulations in Indonesia, the project scope, duration, and location, a hazard analysis, and safety programs to determine the cost of safety in accordance with the present conditions of infrastructure projects in Indonesia. Kamardeen (2019) proposed a conceptual framework for a web-based Occupational Health and Safety (OHS) management system for builders, and Mendis and Nandasena (2016) examined the impact of non-used personal protective equipment on occupational health and safety problems and developed a conceptual framework. Furthermore, Andersson \& Menckel (1995) compared conceptual frameworks related to the prevention of accidents and injuries. Different from the study reports in literature, the proposed integrated conceptual framework is based on four hypotheses, which are explained in detail in the following sections.

\section{Work Accident Analysis and Research Hypothesis}

Work accidents and injuries are important occupational health and safety problems (Jafari et al., 2019). Analyzing past-accident information (Tixier et al., 2002) and developing preventive actions considering accident risks are crucial. An accident model must establish a shared understanding within the organization of how and why accidents happen (Kjellen \& Sklet, 1995). According to Khanzode et al. (2012), the accident analysis based on pastaccident data is considered a biased reactive approach. Andersson \& Menckel (1995) examined 11 conceptual framework models related to measuring accidents and injuries: "primary, secondary, and tertiary prevention", "proactive and reactive primary prevention", "exposure and disposition prevention", "democratic and technocratic prevention", "prevention through intervention", "the Haddon matrix", "Haddon's ten strategies", "active and passive prevention", "prevention as a causal process", "absolute and relative prevention", and "absolute and relative prevention". Among the studies of accident analyses, studies of analyzing accidents in terms of organization, employee, and accident factors by statistical methods (Tatsaki et al., 2019, Erdugan \& Türkan, 2017; Turkkan \& Pala, 2016, Salguero-Caparros et al., 2015, Sanmiquel et al., 2014, Isara \& Ofili, 2012 \& Cheng et al., 2010) and the application of data mining-based approaches to accident analyses (Combertiet et al., 2018, Altunkaynak, 2018, Sanmiquel et al., 2018, Shirali et al., 2018, Gerassis et al., 2016 \& Mutlu \& Altuntas, 2019a) have been conducted. Salguero-Caparros et al. (2019) examined the methods used to analyze occupational accidents and listed 35 different methods. By analyzing occupational accidents, the safety performance can be improved by focusing on the factors causing the accidents (Stemn, 2019, Smirnyakov et al., 2019 \& Vranješ \& Todić, 2019). The increasing number of accidents recorded in digital media has increased the interest in data mining approaches with the development of new technology (Mutlu \& Altuntas, 2019a). In addition, it is recommended that stakeholders such as government, regulators, company, management, staff, and work can be considered while performing accident investigation in complex systems. (Rasmussen, 1997). Therefore, identifying the important factors affecting accidents, considering these factors, determining accident rules in terms of accident outcome variables and effective preventive action plans are proposed to learn from work accidents within the conceptual framework proposed in this paper. Mutlu \& Altuntas (2019a)'s study functions as an example for achieving these benefits. Mutlu \& Altuntas (2019a) used accident data including information related to company, work, staff, etc. for the assessment of occupational risks. The first hypothesis supporting the integrated conceptual framework in this study is as follows:

Hypothesis 1: Developed safety actions affect positively occupational health and safety in-depth analyses of occupational accident records with data mining approaches. 


\section{Hazard and Risk Assessment and Research Hypothesis}

A hazard is defined as an accident and potential situation causing undesirable consequences. (Ericson, 2005, p.15). Hazards are specific to business systems, and the professional experience plays a crucial role in the reliable identification of hazards in the system (Khanzode et al., 2012). Ericsson (2005) likened risks to radio signals and stated that they sometimes appear clear, invisible, or pale. Kahnzado et al. (2012) emphasized the importance of identifying hazards in a reliable way to identify and overcome the risk of injury; they classified the hazard identification methods into three groups: biased reactive, biased proactive, and unbiased proactive approaches. The biased reactive approach relates to the analysis of an accident event after its occurrence. The biased proactive approach is a hazard analysis based on the information on possible hazards and the recorded historical error/danger associated with the system. The unbiased proactive approach is a hazard analysis that is conducted without incident/accident and restrictive assumptions. Details on these approaches can be found in Khanzode et al. (2012). The occurrence probability and severity of the hazard are the most important factors that constitute the risk, and the risk is defined by an uncertainty function of these two factors (Pham, 2011, p.369).

Regarding the studies related to risk analyses and assessments, Tixier et al. (2002) classified the methods into six classes based on the combination of four usual criteria (qualitative, quantitative, deterministic, and probabilistic). Moreover, Marhavilas et al. (2011) classified the classic risk analysis and evaluation methods into three classes: qualitative, quantitative, and hybrid approaches. According to literature, the classical methods do not meet the requirements and must be enhanced to analyze the risks of work environments, which have become more complex (Can \& Toktas, 2018, Goerlandt et al., 2017, Mohsen \& Feresteh, 2017 \& Mutlu \& Altuntas, 2019b). Some researchers have suggested that classical risk analysis and evaluation methods should be developed by hybridizing the methods with fuzzy logic, multi-criteria decision-making methods (Dabbagh \& Yousefi, 2019, Mete et al., 2019, Tepe \& Kaya, 2019, Gul, 2019, Gul et al., 2018, Akyildiz \& Mentes, 2017 \& Gürcanlı \& Müngen, 2009). In 2018, Gul listed 40 methods that integrate risk analysis and assessment methods, multi-criteria decision making, and fuzzy logic approaches and stated that most of the developed methods are based on the FMEA method. However, researchers have criticized that hazard and risk analysis practices are not integrated and that the criteria used in both analysis processes do not overlap (Khanzode \& Maiti, 2012, Raouf, 2004 \& Kjellen \& Sklet, 1995).

The basis for the proposed the conceptual framework is based on articles 8 and 12 of the Occupational Health and Safety Risk Assessment Regulation indicating that it is appropriate to with accident analysis (OHS Risk Assessment Regulation, 2012). In the $8^{\text {th }}$ article of the mentioned regulation, the information that must be collected within the scope of the identification of hazards includes "past accident records" and "near-miss incident" information. In article 12 of the same regulation, it was reported that the risk assessment should be performed again in the event of "occupational accident, occupational disease or incident before the incident". Another important issue is the statement "The risk assessment is carried out by a team created by the employer", as stated in Article 6 of the Occupational Health and Safety Risk Assessment Regulation. In other words, it was stated that the team consisting of the employer or his representative, occupational safety expert, employee representative, support staff, and employees who are knowledgeable about the risks in the workplace should carry out the risk assessment with a participatory perspective. Therefore, the second hypothesis of the conceptual framework proposed in this paper recommends that factors learned from accidents should be considered in risk analyses and evaluations. For example, Mutlu \& Altuntas (2019b) presented an unbiased proactive risk analysis and evaluation approach based on FMEA, which is based on biased proactive features; it can be used in risk analysis and evaluation processes to improve occupational health and safety in production and service systems. Researchers are recommended to integrate Mutlu $\&$ Altuntas (2019b)' results into their analysis and evaluation processes. The reasons for recommending the study of Mutlu \& Altuntas (2019b) to researchers are listed below:

a) The proposed method is based on FMEA method, which meets the need for strong risk assessment method in complex systems (Flaus, 2013, p. 179). 
b) The proposed method complies with the consideration of Rasmussen (1997) principles, which are related to the participation of stakeholders in the risk management process within the scope of "inclusiveness", which is one of the accident principles of multiple actors and levels, external pressure.

c) The proposed method also complies with the ISO $31000(2018$, p.3) which highlights taking into account the information, opinions and perceptions by ensuring the participation of stakeholders in the risk management process within the scope of "inclusiveness", which is one of the risk management principles.

Therefore, the second hypothesis supporting the integrated conceptual framework in this study is as follows:

Hypothesis 2: Factors affecting accidents have a positive impact on occupational health and safety when included in a proactive risk assessment approach.

\section{Risk Prioritization, Rating, and Research Hypothesis}

Risk is a combination of the likelihood of a harm and the severity of that harm (ISO 12100, 2010, p.3). Risk assessment helps to identify, analyze, and evaluate possible riks (Brauer, 2016, p.650). Hazards are identified by risk identification. The purpose of risk identification is to reduce uncertainty in factors that have the potential to cause accidents, injuries, diseases and death. (Brauer, 2016, p.646). Risk analysis has qualitative and quantitative techniques, which are applied to potential hazards, and frequency and severity of risks are generally taken into account (Brauer, 2016, p.647). According to ISO (12100, 2010, p.3), risk analysis is the determination of the framework to be analyzed, the definition of hazards and the prediction of risks. Residual risk means remaining risk after preventive measures are applied. (ISO 12100, 2010, p.3). Risk estimation involves identifying the severity of the possible harm and the probability of occurrence (ISO 12100, 2010, p.3). In addition, Risk evaluation assesses risk aversion and risk acceptance in practice (Brauer, 2016, p.650). According to ISO (12100, 2010, p.3), risk assessment is the stage to decide whether risk reduction targets are achieved based on risk analysis. Risk hierarchy / priority order obtained during the risk analysis phase is used as information that facilitates decision making (Silvestri et al., 2012a). For instance, risk priority is used for various purposes such as increasing organizational benefits (Dodsworth et al., 2007), improving safety by rating fire hazards (Lo, 1999), rating critical equipment for maintenance planning (Mahmoudi et al., 2019), rating health risks according to priority, and improving safety in general (Chang et al., 2012).

In the literature, the use of Multiattribute utility theory (MAUT) and Event Tree Analysis (Garcez \& Almedia, 2013; Brito \& Almedia, 2009), the use of fuzzy logic based FMEA (Yazdi, 2019, Alyami et al., 2019 \& Pillay \& Wang, 2003) and the use of multi criteria decision making based FMEA (AL Mashaqbeh et al., 2019 \& Hu et al., 2019) have been conducted to decrease uncertainty and to enhance the current risk ranking technique. However, different risk priorities for the same hazards can be obtained, which causes failures in case of the use of multiple risk analysis approaches (Gul \& Ak, 2018, Liu et al., 2019, Liu et al., 2017a). This leads to a confusing problem for decision makers. This paper proposes a single risk sequencing order based on the integration of the risk grades to overcome the problem and obtain a more reliable risk priority ranking in the developed conceptual framework. One of the methods that can be used to solve this risk degree problem is TPOP, which was proposed by Bairagi et al. (2015). When the method is applied to a risk analysis and evaluation process, the working principle is based on the use of multiple risk analysis and evaluation methods. By integrating the advantages of different methods, a single risk sequence can be obtained. For example, Mutlu \& Altuntas (2019b) proposed a risk analysis and evaluation method based on the FMEA, FTA, and BIFPET algorithms and compared the results obtained from the FMEA-FTA, FMEA-FTA, and PERT distributions to assess the performance. Single risk ranking can be achieved with the TPOP approach by using the final risk priority rankings obtained by these three different methods. The method is expected to provide great convenience to decision makers and contribute to the improvement of occupational health and safety. Therefore, the third hypothesis supporting the integrated conceptual framework in this study is as follows:

Hypothesis 3: Reliable risk ranking affects occupational health and safety positively. 


\section{Technological Developments in Occupational Health and Safety And Research Hypothesis}

Risks related to occupational health and safety have increased in industries that have become more complex with the technological development (Huang \& Ren, 2010, Myers, 2007). In addition, technological tools have been increasingly used, and new safety technologies have been developed; however, they are not sufficient for improving occupational health and safety (AntwiAfari, 2019, Holte et al., 2018, Gao et al., 2019, Tang et al., 2019, Awolusi et al., 2018 \& Tatić \& Tešić, 2017). The past and present technologies must be accurately analyzed, and information that sheds light on the future must be obtained to use business resources efficiently and assist in investment decisions.

One of the ISO 31000 (2018, p.3) risk management principles is Dynamic which implies that the risks can be estimated, identified, accepted or accepted taking into account that new risks may arise and risks may disappear or turn into another form due to changes in an organization's internal and external environment. Hence, it is thought that the rapid development of safety technologies should be taken into consideration in the process of monitoring and controlling the risks, which contributes to the dynamic nature of the risks.

One of the most important indicators of technological developments is the use of patent documents (e.g., Yakişik \& Çetin, 2014, Tunç, 2008 \& Narin \& Olivastro, 1988). Based on the studies of Song \& Suh (2019) and Jeon \& Suh (2019), use of patent documents in the field of safety technologies is suggested to follow the technological developments in the field of occupational health and safety within the integrated conceptual framework. For example, Durmusoglu (2018)'s results can be used to create a technology forecasting model with patent documents and to identify significant changes. Durmusoglu (2018) used Individual Moving Range control charts based on patent documents to monitor the changes in technology. These researchers have not used the approach in the monitoring process of the changing safety technologies in the field of occupational health and safety and in the development of the forecasting model. The years leading to the significant changes in security technologies can be determined based on the control charts. This way, the factors responsible for the changes can be investigated, and the technologies to be investigated can be determined. The occupational health and safety field is expected to be improved by encouraging the use of safety technologies in practice. Therefore, the fourth hypothesis supporting the integrated conceptual framework in this study is as follows:

Hypothesis 4: Monitoring changes in safety technologies affects the improvement of occupational health and safety positively and promotes the construction of proactive occupational health and safety management systems in practice.

\section{THE PROPOSED CONCEPTUAL FRAMEWORK}

Figure 1 illustrates the proposed conceptual framework for improving occupational health and safety and monitoring and controlling risks. The information and data flow between the approaches of the proposed conceptual framework are presented in Figure 2. The first part in Figure 1 presents the first hypothesis of the proposed conceptual framework, which deals with learning from accidents by analyzing past-accident information (biased reactive hazard analysis). The second part in Figure 1 presents the analysis and assessment of risks and the consideration of the information learned in the previous part (the first part) during the unbiased proactive risk analysis and evaluation process.

The third part in Figure 1 demonstrates how to simplify the decision-making process of security managers or experts with the correct ranking of risks for a single ranking with multiple risk analysis approaches. The proposed conceptual framework encourages technology investors to monitor and control risks and draws attention to the development and changes of safety technologies to improve occupational health and safety in the last part of Figure 1.

The proposed approaches for monitoring and controlling risks and the information flow of the conceptual framework are summarized in Figure 2. A robust occupational health and safety system can be constructed in an organization using the proposed conceptual framework. 


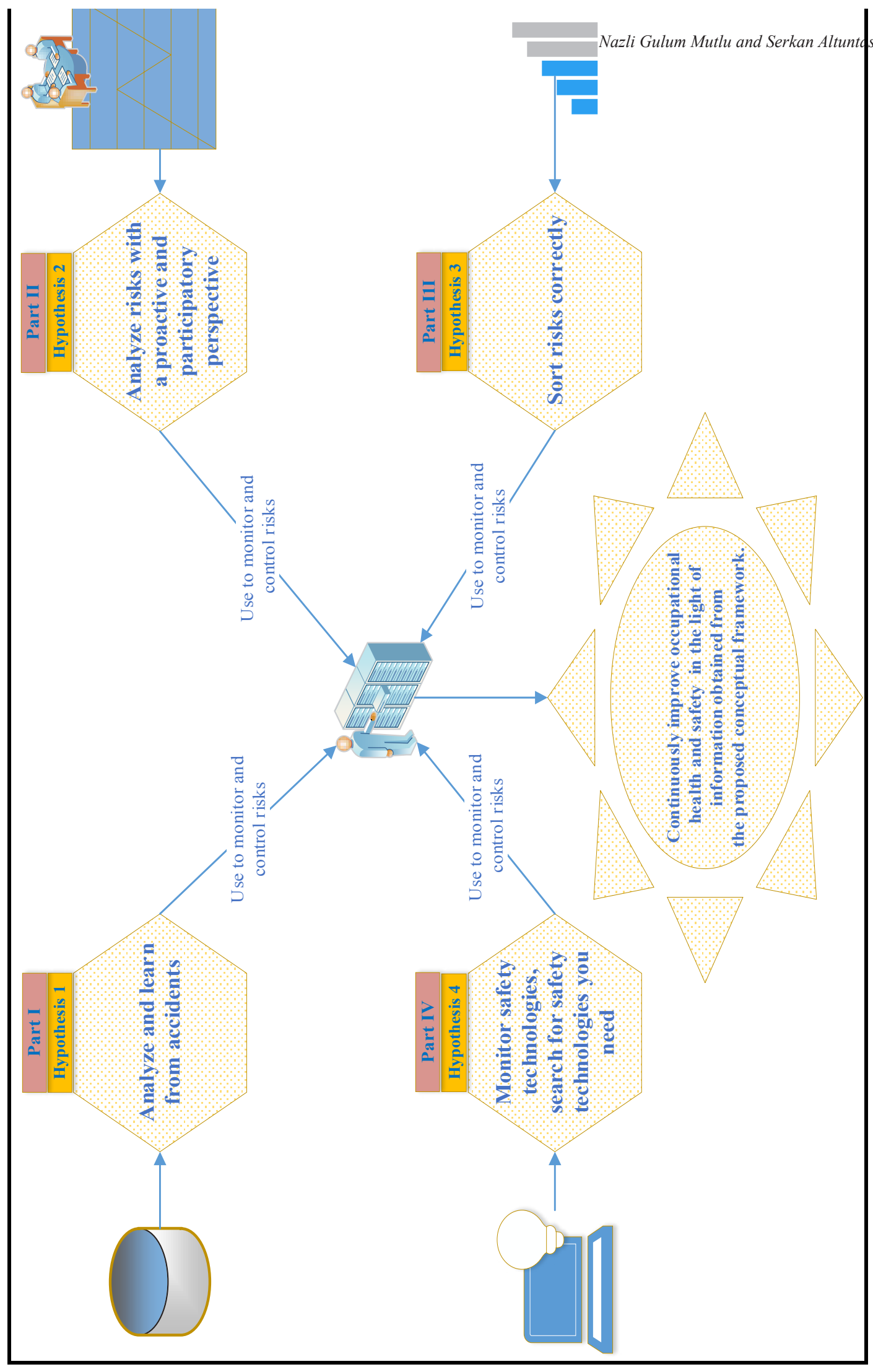




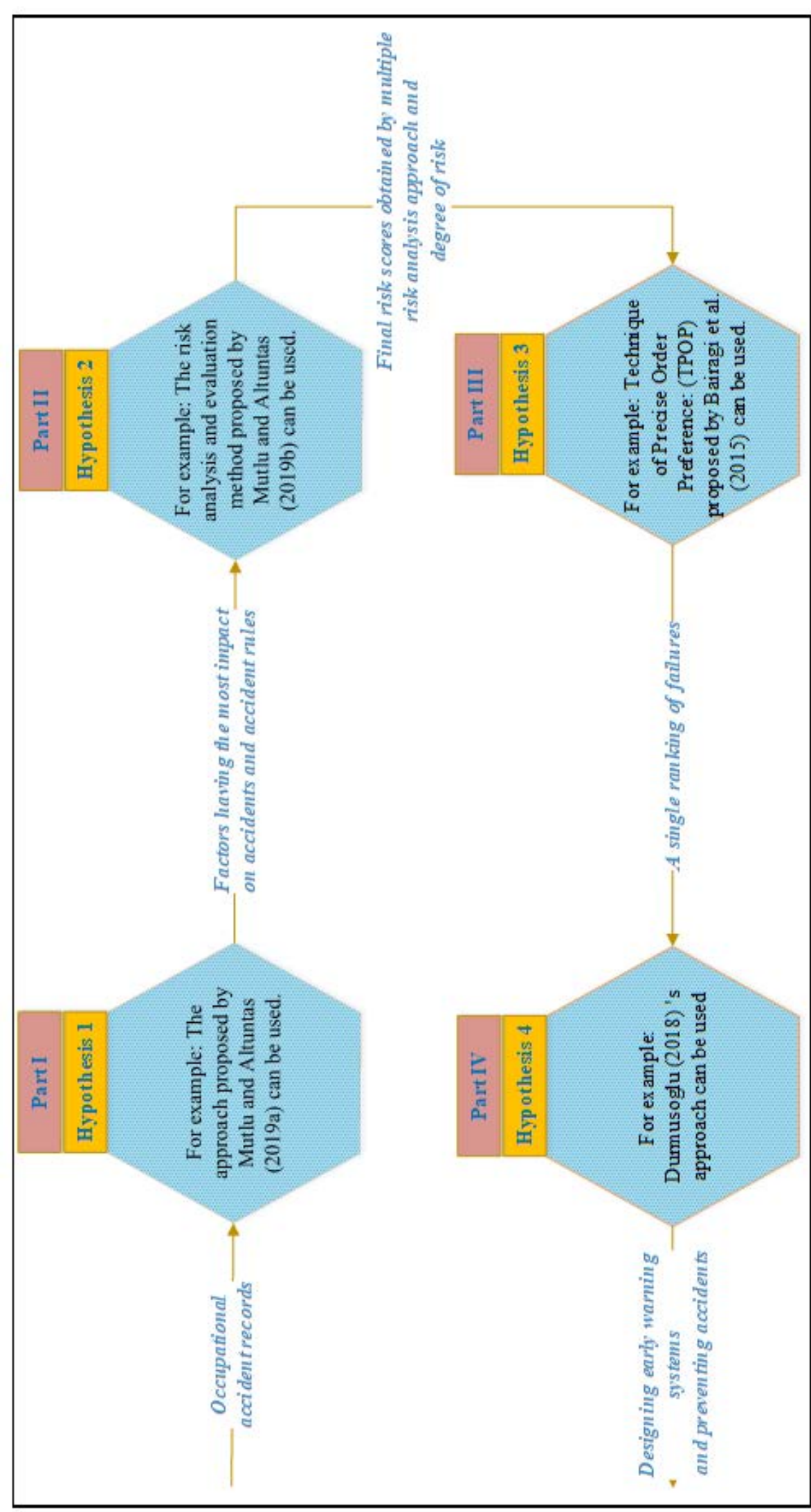

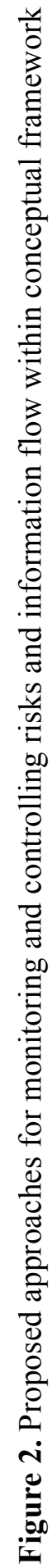




\section{CONCLUSION}

The development of occupational health and safety can be determined by predicting possible hazards and critical factors, monitoring critical factors, and using safe monitoring tools to ensure that they are not exposed to accidents and losses (Pęciłło, 2016). In addition, the systems gain flexibility against risks; thus, the risks and ranking are known, systems that provide continuous risk monitoring are used, and the risk effects can be eliminated without being exposed to losses (Hollnagel et al., 2006). Therefore, understanding the accident structure is crucial for predicting future accidents and developing effective measures by analyzing past-accident data.

In this paper, a conceptual framework for monitoring and controlling risks in occupational health and safety in practice is proposed. It is based on four hypotheses, which focus on important points regarding occupational health and safety in practice. The data and information flow within the proposed conceptual framework support each part to achieve robust occupational health and safety practice in an organization.

The combined use of the proposed solution approaches is expected to integrate the advantages of independently used tools to improve holistic occupational health and safety. This way, decision making can be conducted with minimal cost and maximal efficiency to improve occupational health and safety in practice.

\section{DISCUSSION}

Occupational safety professionals and safety engineers are expected to eliminate the risks of accidents, control safety measures, and develop necessary measures when they know the critical factors and their importance in terms of accident types based on the use of the proposed conceptual framework.

In addition, three important factors should be considered: (1) the risk factors learned from accidents, (2) proactive perspective, and (3) information from all relevant stakeholders to achieve a successful outcome based on the analysis and assessment of risks. Another important step for improving occupational health and safety is starting with the top-priority risk when controlling and developing safety measures to reduce or eliminate risks. Furthermore, the risk priority ranking is of great importance for planning the precautionary costs of company resources. Risks should be assessed correctly. Otherwise, more important risks may be overlooked, and serious losses may occur. Analyzing past-accident information for safety, analyzing and evaluating risks, and correctly ranking risks are as important as monitoring safety technologies and introducing the required technologies to the enterprise.

\section{REFERENCES}

Andersson, R., \& Menckel, E. 1995. On the prevention of accidents and injuries: a comparative analysis of conceptual frameworks. Accident Analysis \& Prevention, 27(6): 757-768.

Akyildiz, H., \& Mentes, A. 2017. An integrated risk assessment based on uncertainty analysis for cargo vessel safety, Safety Science, 92: 34-43.

AL Mashaqbeh, S., Munive-Hernandez, J. E., \& Khurshid Khan, M. 2019. Using EWGM method to optimise the FMEA as a risk assessment methodology. Concurrent Engineering, 27(2): 144-154.

Altunkaynak, B. 2018. A statistical study of occupational accidents in the manufacturing industry in Turkey. International Journal Of Industrial Ergonomics, 66(1): 101-109.

Alyami, H., Yang, Z., Riahi, R., Bonsall, S., \& Wang, J. 2019. Advanced uncertainty modelling for container port risk analysis. Accident Analysis \& Prevention, 123: 411-421. 
Antwi-Afari, M., Li, H., Wong, J., Oladinrin, O., Ge, J., Seo, J. \& Wong, A. 2019. Sensing and warning-based technology applications to improve occupational health and safety in the construction industry: A literature review. Engineering, Construction and Architectural Management, 26(8): 1534-1552.

Aven, T. 2016. Risk assessment and risk management: Review of recent advances on their foundation. European Journal of Operational Research, 253(1): 1-13.

Awolusi, I., Marks, E., \& Hallowell, M. 2018. Wearable technology for personalized construction safety monitoring and trending: Review of applicable devices. Automation in construction, 85: 96-106.

Bastan, M., Baraftabi, L. A., Groesser, S., \& Sheikhahmadi, F. 2018. Analysis of development policies in occupational health and safety management system: A system dynamics approach. Paper presented at the Proceedings of the International Conference on Industrial Engineering and Operations Management, 2018(JUL): 61-64.

Badri, A., Boudreau-Trudel, B., \& Souissi, A. S. 2018. Occupational health and safety in the industry 4.0 era: A cause for major concern? Safety Science, 109: 403-411.

Balaraju, J., Raj, M. G., \& Murthy, C. S. 2019. Fuzzy-FMEA risk evaluation approach for LHD machine-A case study. Journal of Sustainable Mining, 18(4): 257-268.

Braglia, M. 2000. MAFMA: multi-attribute failure mode analysis. International Journal of Quality \& Reliability Management, 17(9): 1017-1033.

Bairagi, B., Dey, B., Sarkar, B., \& Sanyal, S. K. 2015. A De Novo multi-approaches multi-criteria decision making technique with an application in performance evaluation of material handling device. Computers \& Industrial Engineering, 87: 267-282.

Brauer, R. L. 2016. Safety and health for engineers. John Wiley \& Sons.

Brito, A. J., \& de Almeida, A. T. 2009. Multi-attribute risk assessment for risk ranking of natural gas pipelines. Reliability Engineering \& System Safety, 94(2): 187-198.

Can, G. \&Toktas, P. 2018. A novel fuzzy risk matrix based risk assessment approach. Kybernetes, 47(9): 17211751.

Ceylan, H. 2012. Türkiye'deki Elektrik İletim Tesislerinde Meydana Gelen İş Kazalarının Analizi. Ejovoc (Electronic Journal of Vocational Colleges, 2(1): 98-109.

Cheng, C. W., Leu, S. S., Lin, C. C., \& Fan, C. 2010. Characteristic analysis of occupational accidents at small construction enterprises. Safety Science, 48(6): 698-707.

Chang, D. S., Chung, J. H., Sun, K. L., \& Yang, F. C. 2012. A novel approach for evaluating the risk of health care failure modes. Journal of Medical Systems, 36(6): 3967-3974.

Comberti, L., Demichela, M., \& Baldissone, G. 2018. A combined approach for the analysis of large occupational accident databases to support accident-prevention decision making. Safety Science, 106: 191202.

Durmusoglu, A. 2018. Updating technology forecasting models using statistical control charts. Kybernetes, 47(4): 672-688.

Dündar, T. 2018. RFID-based system proposal forenabling the use of personal protective equipment in occupational health and safety", Master Thesis (Supervisors: Assoc. Prof. Dr. Tarık Arıkan Saygıll and Assist. Prof. Dr. Gökhan Kılıç), Izmir University of Economics, İzmir.

Dehghani Madvar, M., Aslani, A., Ahmadi, M. H., \& Karbalaie Ghomi, N. S. 2019. Current status and future forecasting of biofuels technology development. International Journal of Energy Research. 43(3): 1142-1160. 
Dabbagh, R., \& Yousefi, S. 2019. A hybrid decision-making approach based on FCM and MOORA for occupational health and safety risk analysis. Journal of safety research, 71: 111-123.

Dodsworth, M., Connelly, K. E., Ellett, C. J., \& Sharratt, P. 2007. Organizational climate metrics as safety, health and environment performance indicators and an aid to relative risk ranking within industry. Process Safety and Environmental Protection, 85(1): 59-69.

Erdugan, F., \& Türkan, A. H. 2017. Üç Yönlü Kontenjans Tablolarında Log-Lineer Model ile İş Kazası Verilerinin İncelenmesi. Karaelmas Fen ve Mühendislik Dergisi, 7(2): 462-468.

Ericson, C. 2005. Hazard analysis techniques for system safety, A John Wiley \& Sons. INC., Publication.

Fernández, F. B., \& Pérez, M. Á. S. 2015. Analysis and modeling of new and emerging occupational risks in the context of advanced manufacturing processes. Procedia Engineering, 100: 1150-1159.

Flaus, J. M. 2013. Risk analysis: socio-technical and industrial systems. John Wiley \& Sons.

Fitriani, R., \& Latief, Y. 2019, October. A conceptual framework of cost of safety model in infrastructure project based on work breakdown structure (wbs) to improve safety policy in indonesia. In IOP Conference Series: Materials Science and Engineering, 650(1): 012003. IOP Publishing.

Gao, Y., Gonzalez, V. A., \& Yiu, T. W. 2019. The effectiveness of traditional tools and computer-aided technologies for health and safety training in the construction sector: A systematic review", Computers \& Education, Vol. 138, pp. 101-115.

Garcez, T. V., \& De Almeida, A. T. 2013. Multidimensional risk assessment of manhole events as a decision tool for ranking the vaults of an underground electricity distribution system. IEEE transactions on power delivery, 29(2): 624-632.

Goetsch, D. 2015. Ooccupational Safety and Health For Technologists, Engineers, and Managers, 8th edition edition.

Goerlandt, F., Khakzad, N., \& Reniers, G. 2017. Validity and validation of safety-related quantitative risk analysis: A review. Safety Science, 99: 127-139.

Gul, M. 2018. A review of occupational health and safety risk assessment approaches based on multi-criteria decision-making methods and their fuzzy versions. Human and Ecological Risk Assessment: An International Journal, 24(7): 1723-1760.

Gul, M., \& Ak, M. F. 2018. A comparative outline for quantifying risk ratings in occupational health and safety risk assessment. Journal of Cleaner Production, 196: 653-664.

Gul, M. 2019. A fuzzy-based occupational health and safety risk assessment framework and a case study in an international port authority. Journal of Marine Engineering \& Technology, 1-15.

Gul, M., Ak, M. F., \& Guneri, A. F. 2017. Occupational health and safety risk assessment in hospitals: A case study using two-stage fuzzy multi-criteria approach. Human and Ecological Risk Assessment: An International Journal, 23(2): 187-202.

Gul, M., Guneri, A. F., \& Baskan, M. 2018. An occupational risk assessment approach for construction and operation period of wind turbines. Global Journal of Environmental Science and Management, 4(3): 281-298.

Gürcanl,, G., E., Müngen, U., 2009. An occupational safety risk analysis method at construction sites using fuzzy sets. International Journal of Industrial Ergonomics, 39: 371-387.

Gerassis, S., Martín, J. E., García, J. T., Saavedra, A., \& Taboada, J. 2016. Bayesian decision tool for the analysis of occupational accidents in the construction of embankments, Journal of construction engineering and management, 143(2): 04016093. 
Huang, L., \& Ren, J. 2010, May. The negative impact of emerging technology: A Literature Review. In 2010 International Conference on E-Business and E-Government, 2576-2579. IEEE.

Hauke, A., Georgiadou, P., Pinotsi, D., Kallio, H., Lusa, S., \& Malmelin, J. 2011. Emergency services: a literature review on occupational safety and health risks. European Union: European agency for safety and health at work.

Holte, K. A., Follo, G., Kjestveit, K., \& Strate, E. P. 2018, August. Agriculture into the Future: New Technology, New Organisation and New Occupational Health and Safety Risks? In Congress of the International Ergonomics Association, 404-413. Springer, Cham.

Hollnagel, E., Woods, D. D., \& Leveson, N. (Eds.). 2006. Resilience engineering: Concepts and precepts, Ashgate Publishing, Ltd.

Hu, Y. P., You, X. Y., Wang, L., \& Liu, H. C. 2019. An integrated approach for failure mode and effect analysis based on uncertain linguistic GRA-TOPSIS method. Soft Computing, 23(18): 8801-8814.

Isara, A. R., \& Ofili, A. N. 2012. Prevalence of occupational accidents/Injuries among health care workers in a federal medical centre in southern Nigeria. West African journal of medicine, 31(1): 47-51.

ISO 12100, 2010. https://www.iso.org/standard/51528.html.

Jafari, M. J., Barkhordari, A., Eskandari, D., \& Mehrabi, Y. 2019. Relationships between certain individual characteristics and occupational accidents. International Journal of Occupational Safety and Ergonomics, 25(1): 61-65.

Jeon, J. and Suh, Y. 2019. Multiple patent network analysis for identifying safety technology convergence. Data Technologies and Applications, 53(3): 269-285.

Kamardeen, I. 2009, January. Web-based safety knowledge management system for builders: a conceptual framework. In CIB W099: Working together: planning, designing and building a health and safe construction industry. Proceedings of the CIB W099 Conference, 1-11. RMIT University.

Khanzode, V. V., Maiti, J., \& Ray, P. K. 2012. Occupational injury and accident research: A comprehensive review. Safety Science, 50(5): 1355-1367.

Kjellén, U., \& Sklet, S. 1995. Integrating analyses of the risk of occupational accidents into the design process Part I: A review of types of acceptance criteria and risk analysis methods. Safety Science, 18(3): 215-227.

Kutlu, A. C., Ekmekçioğlu, M. 2012. Fuzzy failure modes and effects analysis by using fuzzy TOPSIS-based fuzzy AHP. Expert Systems with Applications, 39: 61-67.

Kruse, T., Veltri, A., \& Branscum, A. 2019. Integrating safety, health and environmental management systems: a conceptual framework for achieving lean enterprise outcomes. Journal of Safety Research, 71: 259-271.

Lo, S. M. 1999. A fire safety assessment system for existing buildings. Fire technology, 35(2): 131-152.

Liu, H. C., Li, Z., Song, W., \& Su, Q. 2017a. Failure mode and effect analysis using cloud model theory and PROMETHEE method. IEEE Transactions on Reliability, 66(4): 1058-1072.

Liu, H. C., Wang, L. E., You, X. Y., \& Wu, S. M. 2019. Failure mode and effect analysis with extended grey relational analysis method in cloud setting. Total Quality Management \& Business Excellence, 30(7-8): 745767.

Mahmoudi, M., Amoozad Mahdiraji, H., Jafarnejad, A. and Safari, H. 2019. Dynamic prioritization of equipment and critical failure modes: An interval-valued intuitionistic fuzzy condition-based model. Kybernetes, 48(9): 1913-1941. 
Marhavilas, P. K., \& Koulouriotis, D. E. 2012. The Deterministic and Stochastic Risk Assessment Techniques in the Work Sites: A FTA-TRF Case Study. Risk Management for the Future-Theory and Cases. 51-66.

Marhavilas, P. K., Koulouriotis, D. E., \& Mitrakas, C. 2011. On the development of a new hybrid risk assessment process using occupational accidents' data: Application on the Greek Public Electric Power Provider. Journal of loss prevention in the process industries, 24(5): 671-687.

Mete, S., Serin, F., Oz, N. E., \& Gul, M. 2019. A decision-support system based on Pythagorean fuzzy VIKOR for occupational risk assessment of a natural gas pipeline construction. Journal of Natural Gas Science and Engineering, 71: 102979.

Mendis, M.V.S. and Nandasena, K.G.D.T. 2016. Non-Usage of Personal Protective Equipment and Occupational Health and Safety Problems: A Study of Sewing Machine Operators in the Apparel Industry of Sri Lanka. 7th International Conference on Business \& Information ICBI - 2016, Faculty of Commerce and Management Studies, University of Kelaniya, Sri Lanka. 45.

Moraru, R. I. 2012. Current trends and future developments in occupational health and safety risk management. Risk Management for the Future-Theory and Cases, 10: 1809.

Mohsen, O., \& Fereshteh, N. 2017. An extended VIKOR method based on entropy measure for the failure modes risk assessment-A case study of the geothermal power plant (GPP). Safety Science, 92: 160-172.

Myers, M. L. 2007. Anticipation of risks and benefits of emerging technologies: A prospective analysis method, Human and Ecological Risk Assessment: An International Journal, 13(5): 1042-1052.

Mutlu, N. G., \& Altuntas, S. 2019a. Assessment of occupational risks In Turkish manufacturing systems with data-driven models. Journal of Manufacturing Systems, 53: 169-182.

Mutlu, N. G., \& Altuntas, S. 2019b. Risk analysis for occupational safety and health in the textile industry: Integration of FMEA, FTA, and BIFPET methods. International Journal of Industrial Ergonomics, 72: 222240.

Narin, F., \& Olivastro, D. 1988. Technology indicators based on patents and patent citations, In Handbook of quantitative studies of science and technology, 465-507. Elsevier.

Niu, Y., Lu, W., Xue, F., Liu, D., Chen, K., Fang, D., \& Anumba, C. 2019. Towards the "third wave": An SCO-enabled occupational health and safety management system for construction. Safety Sience, 111: 213223.

Wu, D., \& Li, Z. 2019. Work safety success theory based on dynamic safety entropy model Safety Science, 113: 438-444.

Oz, N. E., Mete, S., Serin, F., \& Gul, M. 2019. Risk assessment for clearing and grading process of a natural gas pipeline project: An extended TOPSIS model with Pythagorean fuzzy sets for prioritizing hazards, Human and Ecological Risk Assessment: An International Journal, 25(6): 1615-1632.

Ouédraogo, A., Groso, A., \& Meyer, T. 2011. Risk analysis in research environment-Part I: Modeling lab criticity index using improved risk priority number, Safety Science, 49(6): 778-784.

OHS Risk Assessment Regulation, 2012. http://www.resmigazete.gov.tr/eskiler/2012/12/20121229.htm. Accessed on 28.01.2020.

Pham, H. (Ed.). 2011. Safety and Risk Modeling and Its Applications, Springer Science \& Business Media.

Pęcillo, M. 2016. The resilience engineering concept in enterprises with and without occupational safety and health management systems. Safety Science, 82: 190-198. 
Podgórski, D. 2015. Measuring operational performance of OSH management system-A demonstration of AHPbased selection of leading key performance indicators. Safety Science, 73: 146-166.

Podgorski, D., Majchrzycka, K., Dąbrowska, A., Gralewicz, G., \& Okrasa, M. 2017. Towards a conceptual framework of OSH risk management in smart working environments based on smart PPE, ambient intelligence and the Internet of Things Technologies. International Journal of Occupational Safety and Ergonomics, 23(1): 1-20.

Pillay, A., \& Wang, J. 2003. Modified failure mode and effects analysis using approximate reasoning. Reliability Engineering \& System Safety, 79(1): 69-85.

Raouf, A. 2004. Productivity enhancement using safety and maintenance integration: An overview. Kybernetes, 33(7): 1116-1126.

Rasmussen, J. 1997. Risk management in a dynamic society: a modelling problem. Safety Science, 27(2-3): 183213.

Ristić, D. 2013. A tool for risk assessment. Safety Engineering Journal, 3(3): 121-127.

Salguero-Caparros, F., Suarez-Cebador, M., Rubio-Romero, J. C., \& Carrillo-Castrillo, J. A. 2019. Methodologies For Investigating Occupational Accidents And Their Use In Occupational Health And Safety Research Literature Review. Environmental Engineering and Management Journal, 18(3): 665-683.

Sachdeva, A., Kumar, P., \& Kumar, D. 2009, December. Maintenance criticality analysis using TOPSIS. In 2009 IEEE International Conference on Industrial Engineering and Engineering Management, 199-203. IEEE.

Sarkar, S., Vinay, S., Raj, R., Maiti, J., \& Mitra, P. 2019. Application of optimized machine learning techniques for prediction of occupational accidents, Computers \& Operations Research, 106: 210-224.

Sarkar, S., Vinay, S., \& Maiti, J. 2016b, March. Text mining based safety risk assessment and prediction of occupational accidents in a steel plant. In 2016 International Conference on Computational Techniques in Information and Communication Technologies (ICCTICT), 439-444. IEEE.

Salguero-Caparros, F., Suarez-Cebador, M., \& Rubio-Romero, J. C. 2015. Analysis of investigation reports on occupational accidents. Safety Science, 72: 329-336.

Sanmiquel, L., Rossell, J. M., Vintró, C., \& Freijo, M. 2014. Influence of occupational safety management on the incidence rate of occupational accidents in the Spanish industrial and ornamental stone mining. Work, 49(2): 307-314.

Sanmiquel, L., Bascompta, M., Rossell, J., Anticoi, H., \& Guash, E. 2018. Analysis of occupational accidents in underground and surface mining in Spain using data-mining techniques. International journal of environmental research and public health, 15(3): 462.

Shin, D. P., Park, Y. J., Seo, J., \& Lee, D. E. 2018. Association rules mined from construction accident data. KSCE Journal of Civil Engineering, 22(4): 1027-1039.

Shirali, G. A., Noroozi, M. V., \& Malehi, A. S. 2018. Predicting the outcome of occupational accidents by CART and CHAID methods at a steel factory in Iran. Journal of Public Health Research, 7(2): 74-80.

Singpurwalla, N. D., \& Wilson, S. P. 2008. Mathematics of Risk and Reliability: A Select History, Encyclopedia of Quantitative Risk Analysis and Assessment.

Silvestri, A., De Felice, F., \& Petrillo, A. 2012a. Multi-criteria risk analysis to improve safety in manufacturing systems. International Journal of Production Research, 50(17): 4806-4821. 
Swaen, G. M. H., Van Amelsvoort, L. G. P. M., Bültmann, U., \& Kant, I. J. 2003. Fatigue as a risk factor for being injured in an occupational accident: results from the Maastricht Cohort Study. Occupational and environmental medicine, 60(1): i88-i92.

Song, W., Ming, X., Wu, Z., \& Zhu, B. 2013. Failure modes and effects analysis using integrated weight-based fuzzy TOPSIS. International Journal of Computer Integrated Manufacturing. 26(12): 1172-1186.

Song, B., \& Suh, Y. 2019. Identifying convergence fields and technologies for industrial safety: LDA-based network analysis. Technological Forecasting and Social Change, 138: 115-126.

Stemn, E. 2019. Analysis of injuries in the Ghanaian mining industry and priority areas for research", Safety and Health at Work, 10(2): 151-165.

Smirnyakov, V. V., Smirnyakova, V. V., Pekarchuk, D. S., \& Orlov, F. A. 2019. Analysis of Methane and Dust Explosions in Modern Coal Mines in Russia. International Journal of Civil Engineering and Technology, 10(2): 1917-1929.

Tang, N., Hu, H., Xu, F., \& Zhu, F. 2019. Personalized safety instruction system for construction site based on internet technology. Safety Science, 116: 161-169.

Tatsaki, E., Sgourou, E., Katsakiori, P., Konsta, I., \& Gerasimou, S. 2019. The impact of occupational accidents and gross domestic product on the sanctions imposed by the Greek OSH Inspectorate. Safety Science,115: 349-352.

Tatić, D., \& Tešić, B. 2017. The application of augmented reality technologies for the improvement of occupational safety in an industrial environment. Computers in Industry, 85: 1-10.

Tixier, J., Dusserre, G., Salvi, O., \& Gaston, D. 2002. Review of 62 risk analysis methodologies of industrial plants. Journal of Loss Prevention in The Process Industries, 15(4): 291-303.

Tepe, S., \& Kaya, İ. 2019. A fuzzy-based risk assessment model for evaluations of hazards with a real-case study. Human and Ecological Risk Assessment: An International Journal, 26(2): 512-537.

Tunç, H. 2008. As an innovation indicator patent and Türkiye patent performance, Master Thesis (Supervisors: Assist. Prof. Dr. Mesut Albeni), Süleyman Demirel University, Isparta.

Turkkan, A., \& Pala, K. 2016. Trends in occupational injuries and fatality in Turkey. International Journal Of Occupational Safety And Ergonomics, 22(4): 457-462.

Vranješ, B., \& Todić, M. 2019. A model of analysis of the occupational safety and health system in the production system. Journal of Applied Engineering Science, 17(3): 264-272.

Yavuz, Ö. Ç. 2018. Determination of the activities of occupational health and safety measures with eye tracking device. Master Thesis (Supervisors: Assoc. Prof. Dr. Ersin Karaman), Atatürk University, Erzurum.

Yazdi, M. 2019. Improving failure mode and effect analysis (FMEA) with consideration of uncertainty handling as an interactive approach. International Journal on Interactive Design and Manufacturing (IJIDeM), 13(2): 441-458.

ISO 31000, 2018. https://www.iso.org/iso-31000-risk-management.html. Accessed on 16 Feb 2020.

Yakişik, H., \& Çetin, A. 2014. Eğitim, Sağlık ve Teknoloji Düzeyinin Ekonomik Büyüme Üzerindeki Etkisi: ARDL Sınır Test Yaklaşımı. Sosyoekonomi, 21(21): 169-186.

Zhang, H. J., Zhou, Y., \& Gan, Q. H. 2019a. An Extended PROMETHEE-II-Based Risk Prioritization Method for Equipment Failures in the Geothermal Power Plant, International Journal of Fuzzy Systems, 21(8): 24902509. 
Zhang, J., Chen, X., \& Sun, Q. 2019b. A Safety Performance Assessment Framework for the Petroleum Industry's Sustainable Development Based on FAHP-FCE and Human Factors. Sustainability, 11(13): 1-20.

Zhou, L. J., Cao, Q. G., Yu, K., Wang, L. L., \& Wang, H. B. 2018. Research on occupational safety, health management and risk control technology in coal mines. International Journal of Environmental Research and Public Health, 15(5): 1-13. 